\title{
Fluorescence decay time distribution analysis of cyclic enkephalin analogues; Influence of solvent and Leu configuration in position 5 on conformation ${ }^{\star}$
}

\author{
Joanna Malicka ${ }^{1}$, Robert Ganzynkowicz ${ }^{1}$, Małgorzata Groth ${ }^{1}$, Cezary Czaplewski ${ }^{1}$, \\ Jerzy Karolczak ${ }^{2}$, Adam Liwo ${ }^{1}$ and Wiesław Wiczk ${ }^{1 凶}$
}

${ }^{1}$ Faculty of Chemistry, University of Gdańsk, Gdańsk; ${ }^{2}$ Quantum Electronic Laboratory, Faculty of
Physics, Adam Mickiewicz University, Poznañ, Poland

Received: 26 December, 2000; revised: 13 February, 2001; accepted: 15 February, 2001

Key words: enkephalin, fluorescence, energy transfer, lifetime distribution, conformation

\begin{abstract}
Lifetime distribution analysis were performed to study the influence of Leu configuration in position 5 on changes of the peptide chain of cyclic analogues of enkephalins containing a fluorescence donor and acceptor in different solvents. The configuration change of Leu5 in all the analogues of enkephalins studied which contain donor-acceptor pairs has no apparent influence on Trp lifetime distributions. In contrast, there is a significant solvent effect on the shape of lifetime distribution.
\end{abstract}

The opioid system plays a crucial role in analgesic action. The main elements of this system are endogenous peptides (enkephalins, endomorphins, $\beta$-endorphin, dynorphins) which are the natural ligands for opioid receptors $(\mu, \delta, \kappa)$. The $\mu$-opioid receptors have a great significance in an- algesic action. Structure-biological activity analysis of opioid peptide analogues has shown that rigidifying the peptide chain (which is accomplished by cyclization) results in an increase of their affinity for opioid receptors, probably by stabilizing the bioactive conformation(s) [1, 2]. Mu-

\footnotetext{
‡ Presented at International Conference on “Conformation of Peptides, Proteins and Nucleic Acids”, Debrzyno, Poland, 2000 .

${ }_{\text {This work was supported by Grant 1210/T09/99/16 and DS/8372-4-0138-0 from the State Committee for Scientific Re- }}$ search (KBN, Poland).

${ }^{凶}$ Corresponding author: Wiesław Wiczk, Faculty of Chemistry, University of Gdańsk, J. Sobieskiego 18, 80-952 Gdańsk; phone (48 58) 345 0353, fax: (48 58) 341 0357; e-mail: ww@chemik.chem.univ.gda.pl

Abbreviations: $\mathrm{MeOH}$, methanol; $\mathrm{MeCN}$, acetonitrile; $\mathrm{Me}_{2} \mathrm{SO}$, dimethyl sulfoxide; Dns, 5-dimethylaminonaphtalene-1-sulfonyl (dansyl); Phe $\left(\mathrm{p}-\mathrm{NO}_{2}\right), p$-nitrophenylalanine; Dab, $\alpha, \gamma$-diaminobutyric acid; Dns-[L-EN], Dns-cyclo[D-Dab ${ }^{2}-\mathrm{Gly}^{3}{ }^{2} \operatorname{Trp}_{3}^{4}-\mathrm{Leu}_{4}^{5}$ ]; Dns-[D-EN], Dns-cyclo[D-Dab ${ }^{2}-\mathrm{Gly}^{3}-\mathrm{Trp}^{4}$-D-Leu ${ }^{5}$ ]; $\mathrm{F}\left(\mathrm{NO}_{2}\right)-[\mathrm{L}-\mathrm{EN}]$,

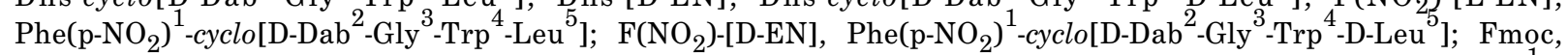
fluorene-9-yl-methoxycarbonyl; HBTU, 2-(1H-benzotriazol-1-yl)-1,1,3,3-tetramethyluronium hexafluorophosphate; ${ }^{1} \mathrm{H}$ NMR COSY, hydrogen nuclear magnetic resonance correlation spectroscopy; RP-HPLC, reversed phase high performance liquid chromatography; FAB-MS, fast atom bombardment mass spectrometry.
} 
tual orientation and the distance between the aromatic side chains, as well as their mobility are also important [3-8]. In conformational studies of the opioid peptides, NMR and fluorescence spectroscopy methods and theoretical calculations are widely used. Fluorescence lifetime distribution analysis is one of the fluorescence methods used in the determination of the conformational space of the fluorophores [9-12]. This method gives information on conformational differences of the main peptide chain, (number of modes of distributions) and conformational freedom of the chromophores which characterize a particular family of conformations (width of the distributions). Although this method gives only a qualitative description of the conformational space, it enables a comparison with the data obtained with other methods, (for example, Förster resonance energy transfer (FRET) [13, 14] or molecular dynamics $[3,5,15])$. The FRET methods give qualitative information about distance and distance distribution between chromophores, but it is restricted by the assumption of a given functional form of the distribution (Gaussian or Lorentzian). This limitation is not imposed in the case of the lifetime distribution methods based on the maximum entropy approach.

We applied the lifetime distribution analysis of the tryptophan fluorophore to study the influence of the solvent $\left(\mathrm{H}_{2} \mathrm{O}, \mathrm{MeOH}, \mathrm{MeCN}\right.$ and $\left.\mathrm{Me}_{2} \mathrm{SO}\right)$ and the configuration of leucine in position 5 on the conformation of the following cyclic analogues
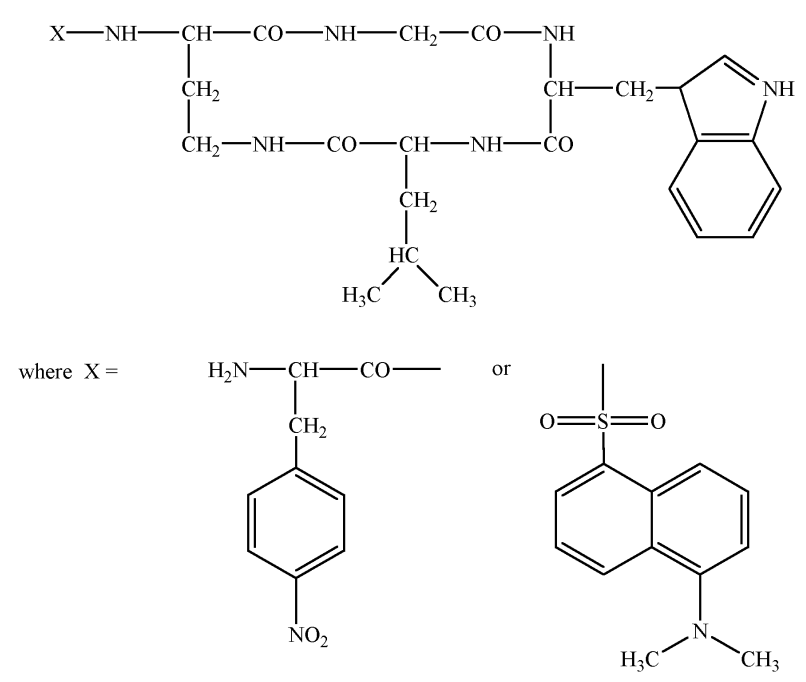

Figure 1. Structure of the cyclic enkephalin analogues considered in this study. of enkephalins containing a fluorescence energy donor (Trp) and acceptor (Dns or Phe(p-NO2)): Dns-[L-EN], F(NO ${ }_{2}$ )-[L-EN], Dns-[D-EN], F(NO 2 )[D-EN].

The structure of the cyclic enkephalin analogues studied is presented in Fig. 1.

The selection of two enkephalin analogues differing in $\mathrm{Leu}^{5}$ configuration for this studies was caused by their different biological activity [5]. In our studies we used the solvents possessing diverse polarity and ability to hydrogen bond formation to mimic the possible microenvironment of the receptor pocket.

\section{THEORY}

The theory of lifetime distribution calculation is described in many papers [9-11, 16, 17]; therefore we present only a brief description here. Fluorescence intensity decays are usually described as sums of individual exponentials. The intensity decay following an infinitesimal pulse excitation ( $\delta$-function) is described by:

$I(t)=\sum_{i} \alpha_{i} e^{-t / \tau_{i}}$

where $\tau_{\mathrm{i}}, \mathrm{i}=1,2,3$, are the individual decay times and $\alpha_{\mathrm{i}}, \mathrm{i}=1,2,3$, the associated pre-exponential factors normalized to unity

$\left(\sum_{i} \alpha_{i}=1.0\right)$.

Now let us consider an alternative model in which the $\alpha_{\mathrm{i}}, \mathrm{i}=1,2, \ldots$, values are not discrete amplitudes corresponding to decay times $\tau_{\mathrm{i}}, \mathrm{i}=1,2, \ldots$, but are described by a continuous distribution $\alpha(\tau)$. The intensity decay then contains components of each lifetime $(\tau)$ with amplitude $\alpha(\tau)$. The total fluorescence intensity decay $I(t)$ is expressed by Eqn. (2):

$I(t)=\int_{\tau=0}^{\infty} \alpha(\tau) e^{-t / \tau} d \tau$

where $\int \alpha(\tau) d \tau=1.0$. At present no theoretical model exists to predict the $\alpha(\tau)$ distributions and the available experimental data do not suggest any general functional form. Hence arbitrarily selected Gaussian or Lorentzian distributions are 
used [10, 16-18]. An alternative approach is not to assume any functional form of $\alpha(\tau)$, but to determine it from the experimental data. This approach is superior in that it makes no assumptions about the shape of the distribution. Two general algorithms: the maximum entropy method [11, 12, 19-22] and the exponential series methods are used for such calculations [23, 24]. For time-correlated single photon counting the measured fluorescence decay $F(t)$ is a convolution of the instrument response function $R(t)$ and the intensity decay function $I(t)$ :

$F(t)=\int_{0}^{t} R(s+\delta) I(t-s) d s$

where $\delta$ is the time shift parameter which takes care of the experimental or computational artifacts which cause an artificial time-shift of the calculated function with respect to experimental data. $I(t)$ is the theoretical intensity decay function, a continuous distribution of lifetimes, as described in equation (2). $\alpha(\tau)$ is the distribution function which is to be determined. The quality of the fit to experimental data is checked by the $\chi^{2}$ statistics:

$\chi^{2}=(1 / M) \sum_{i=1}^{N}\left\{F_{e}\left(t_{i}\right)-F_{e}\left(t_{i}\right)\right\}^{2} / \sigma_{\mathrm{l}}^{2} \approx 1.0$

where $F_{\mathrm{c}}\left(t_{\mathrm{i}}\right)$ is the calculated fluorescence decay at time $t_{i}, F_{\mathrm{e}}\left(t_{\mathrm{i}}\right)$ is the measured decay at time $t_{\mathrm{i}}, \sigma_{\mathrm{i}}$ is the standard deviation for the $\mathrm{i}$-th data point and $\mathrm{M}$ is the number of the degrees of freedom. Usually the good criterion of $\chi^{2} \approx 1.0$ could be obtained for many different distributions of $\alpha(\tau)$. The optimum is the one which fits data adequately $\left(\chi^{2} \approx 1.0\right)$ and maximizes the value of the Shanon-Jaynes entropy function $S$, as defined below:

$S=-\sum p_{i} \log p_{i}$

where $p_{i}=\alpha_{\mathrm{i}} / \Sigma \alpha_{\mathrm{i}}$. If there is a priori knowledge about the distribution $\left(\mathrm{m}_{\mathrm{i}}\right)$, equation (5) is modified as follows:

$S=-\sum p_{i} \log \left(p_{i} / m_{i}\right)$

If the $\chi^{2}$ criterion is satisfied for many distributions, then the maximum entropy criterion selects that distribution which contains the minimum number of peaks of maximal width in the distribution.

\section{MATERIALS AND METHODS}

Synthesis. Linear precursors of peptides (Dns-[L-EN], Dns-[D-EN], F(NO 2 )-[L-EN], F(NO 2$)$ [D-EN]) were synthesized by solid-phase methodology using the Fmoc chemistry [25]. The cyclization was performed using HBTU [26]. The peptides were purified by means of the preparative RP-HPLC. The homogeneity and molecular constitution of the compounds were assessed by analytical RP-HPLC and FAB-MS, and ${ }^{1} \mathrm{H}-\mathrm{NMR}$ COSY spectroscopy.

Time-resolved fluorescence measurements. Fluorescence decay times were measured using a time correlated single-photon counting apparatus at the Laboratory of Ultrafast Laser Spectroscopy, Adam Mickiewicz University (Poznań, Poland). The excitation source $\left(\lambda_{\mathrm{ex}}=280 \mathrm{~nm}\right)$ was a pico/femtosecond laser system (Ti:Saphire "Tsunami" laser pumped with an argon ion laser "BeamLok" 2060) [27]. The emission was detected with a magic angle polarizer at an emission wavelength of $\lambda_{\mathrm{em}}=340 \mathrm{~nm}$. A Ludox solution was used to collect the instrument response. All measurements were performed at $20^{\circ} \mathrm{C}$ in water, methanol, acetonitrile and $\mathrm{Me}_{2} \mathrm{SO}$. For lifetime distribution calculation the software provided by Edinburgh Analytical Instruments was used.

\section{RESULTS AND DISCUSSION}

If the donor and the acceptor remain at a fixed distance the decay of the donor is accelerated by energy transfer, without changing its mono-exponential time dependence. However, if there is a range of donor-acceptor distances, then a range of transfer rates, and hence a distribution of decay times should be observed. If two unique distance distributions are present one should expect a bimodal time distribution. To check how the solvent and different Leu configuration in position 5 influence the distance between the donor in posi- 
tion 4 (Trp) and the acceptor (Dns or Phe $\left(\mathrm{NO}_{2}\right)$ ) in position 1 in the cyclic analogues of enkephalin considered in this study we measured the fluorescence decay times of the donor in the presence of the acceptor in four different solvents $\left(\mathrm{H}_{2} \mathrm{O}\right.$, $\mathrm{MeOH}, \mathrm{MeCN}, \mathrm{Me}_{2} \mathrm{SO}$ ). Fluorescence lifetime tor pairs has no apparent influence on the Trp lifetime distributions. In contrast, there is a significant solvent effect on the shape of the lifetime distribution. In less polar solvents $(\mathrm{MeOH}$, $\mathrm{MeCN}$ ) the distributions are asymmetric, uni- or bimodal; in bimodal distributions the long-life-

Table 1. Lifetimes distribution parameters of Trp fluorescence (average fluorescence lifetime decays $(\tau)$ and amplitudes ( $f$ ) of particular components) of cyclic enkephalin analogues in different solvents

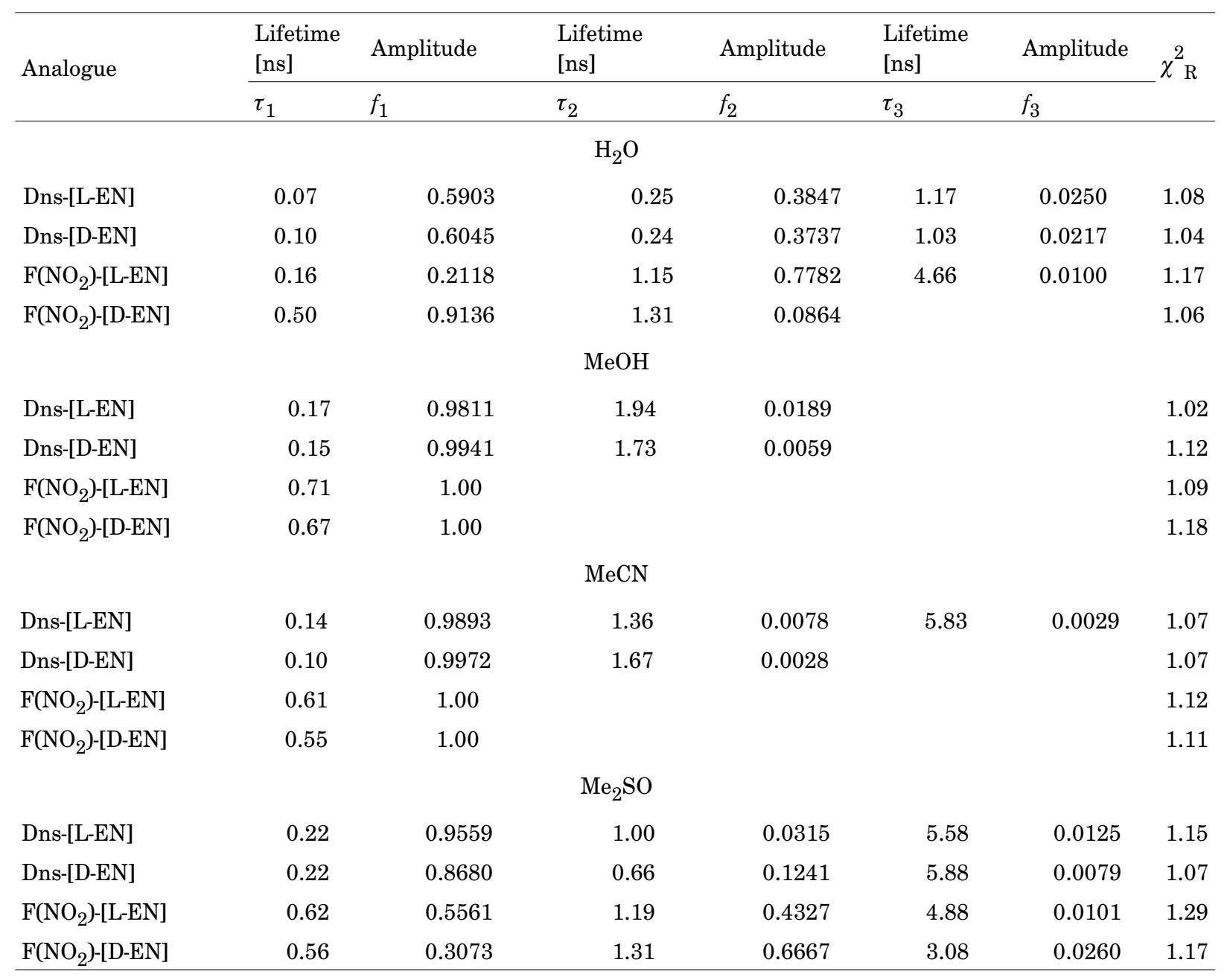

distribution parameters for cyclic enkephalin analogues containing the energy donor (Trp) and the acceptors (Dns or Phe $\left(\mathrm{NO}_{2}\right)$ ) calculated on the basis of the measured fluorescence intensity decay are presented in Table 1 and in a graphical form in Figs. 2 and 3. The presence of the energy acceptor results in a significant decrease of the fluorescence lifetime of tryptophan compared to the isolated donor [28].

The configuration of Leu ${ }^{5}$ in all the analogues of enkephalins studied which contain donor-accep- time components have small amplitudes (0.3-2\%). The width of the distributions is higher in the dansyl containing enkephalin analogues. In more polar solvents the number of distribution components increases. In Dns-[L or D-EN] they are narrow and well separated. The short-lifetime components have a higher amplitude than the long-lifetime ones. The conformational space of the peptides studied in $\mathrm{MeCN}$ and $\mathrm{MeOH}$ can be described in terms of a single conformational family, in which the side chains of the aromatic amino 
a

b
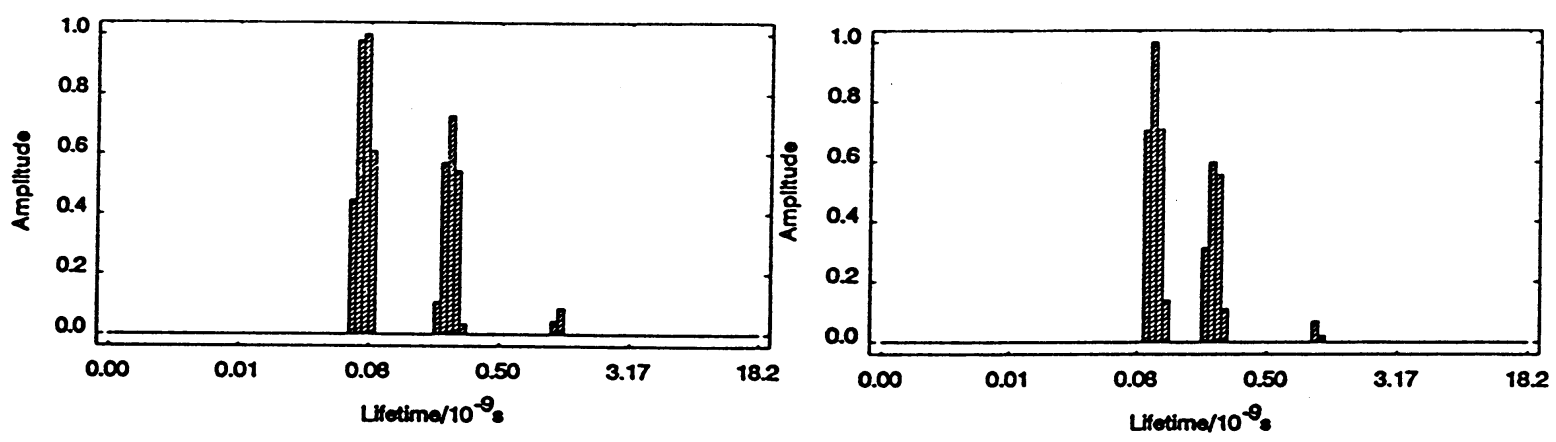

C

$\mathrm{d}$
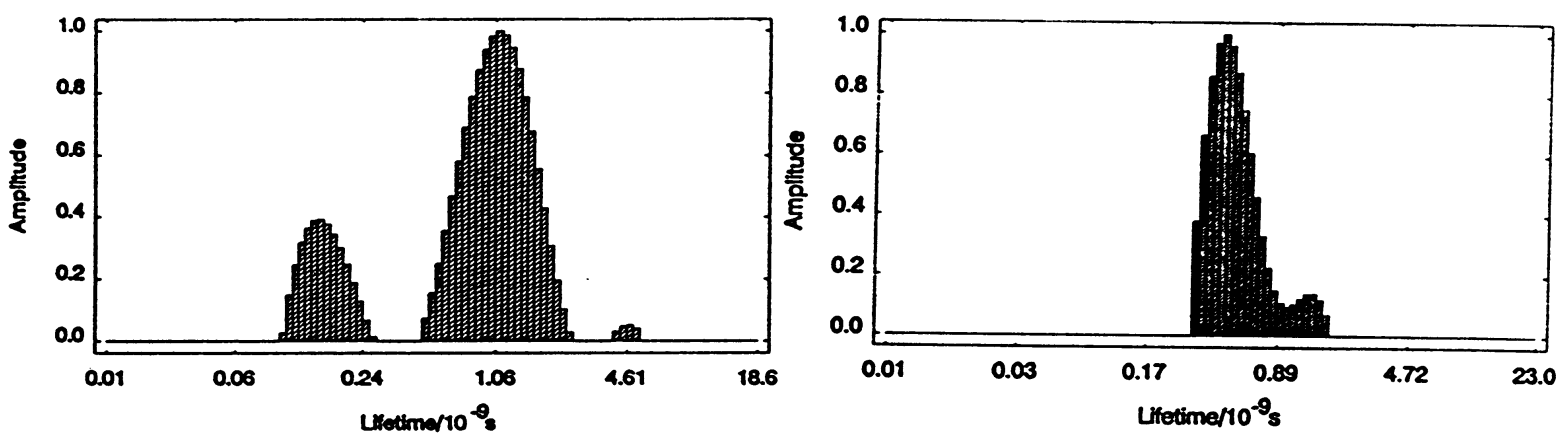

e

$\mathrm{f}$
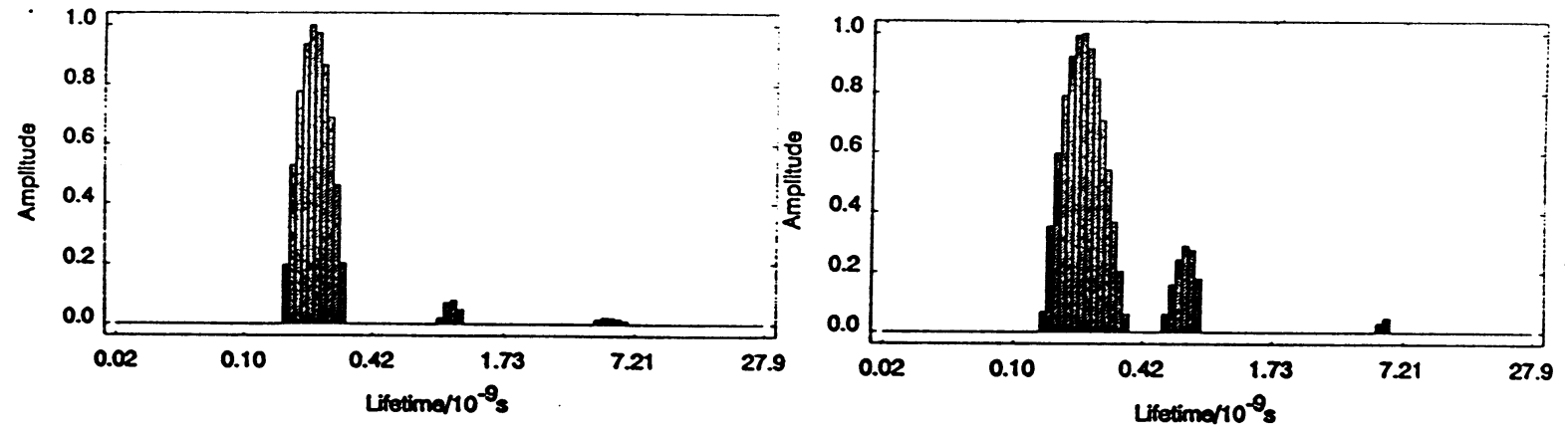

$\mathrm{g}$

h
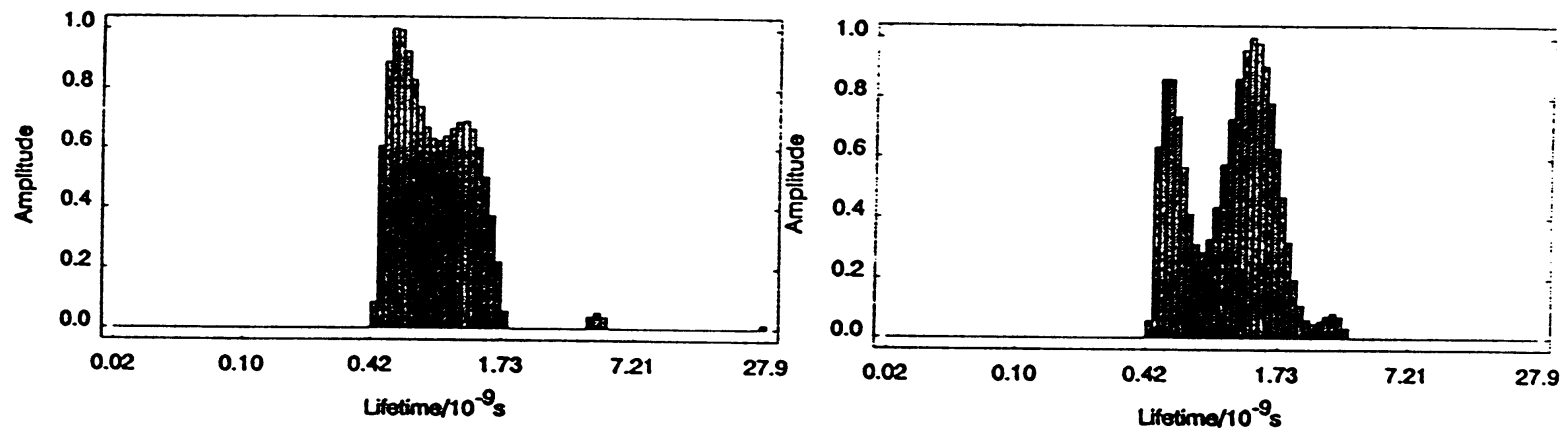

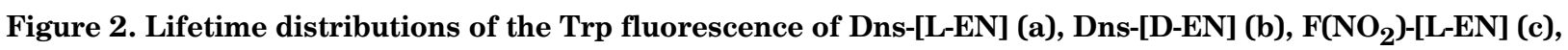
$\mathrm{F}\left(\mathrm{NO}_{2}\right)$-[D-EN] (d) in water and Dns-[L-EN] (e), Dns-[D-EN] (f), $\mathrm{F}\left(\mathrm{NO}_{2}\right)$-[L-EN] (g), $\mathrm{F}\left(\mathrm{NO}_{2}\right)$-[D-EN] (h) in $\mathrm{Me}_{2} \mathrm{SO}_{\text {. }}$ 
a

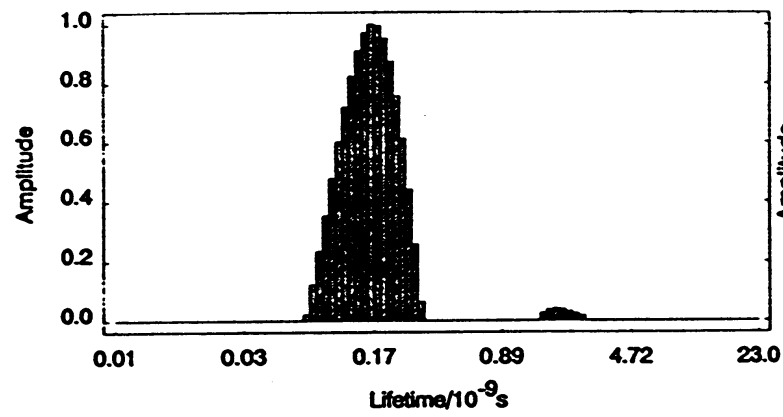

C

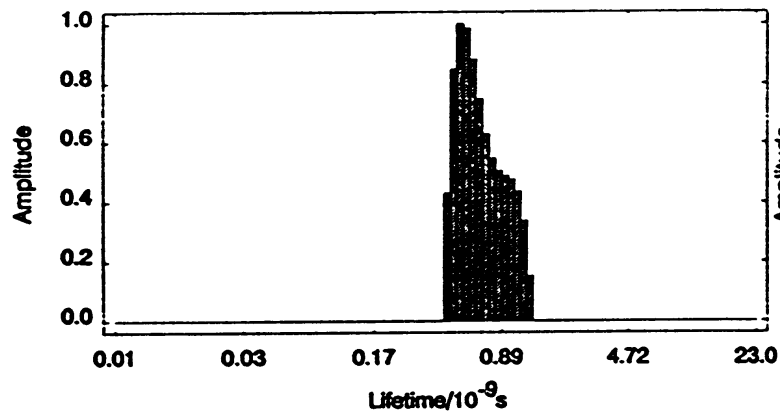

e

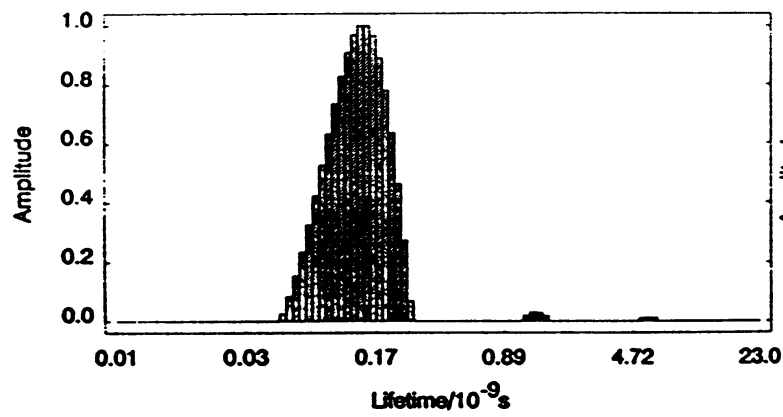

g

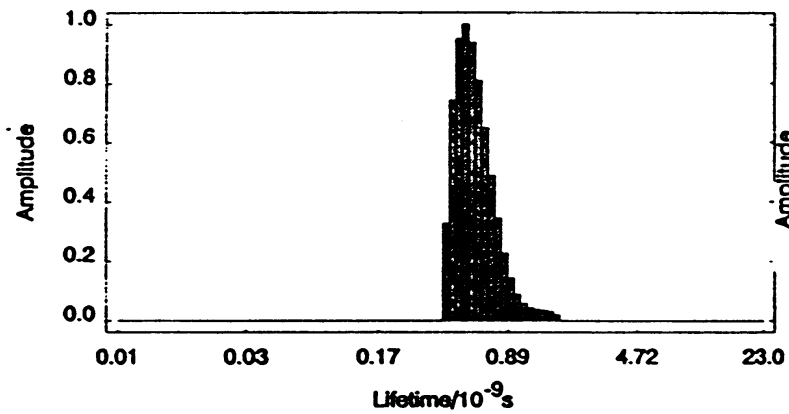

b

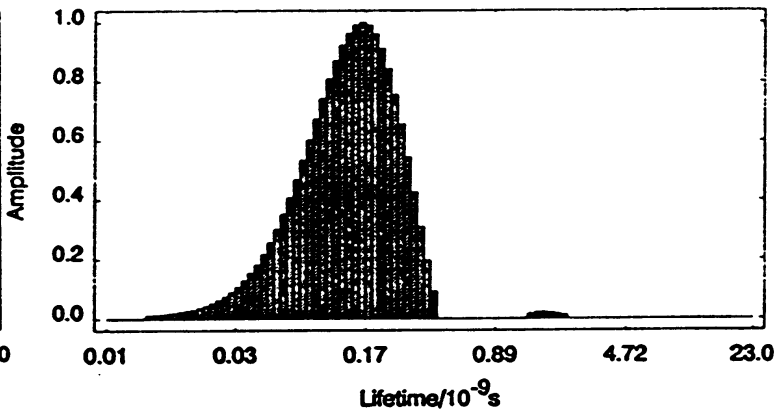

d

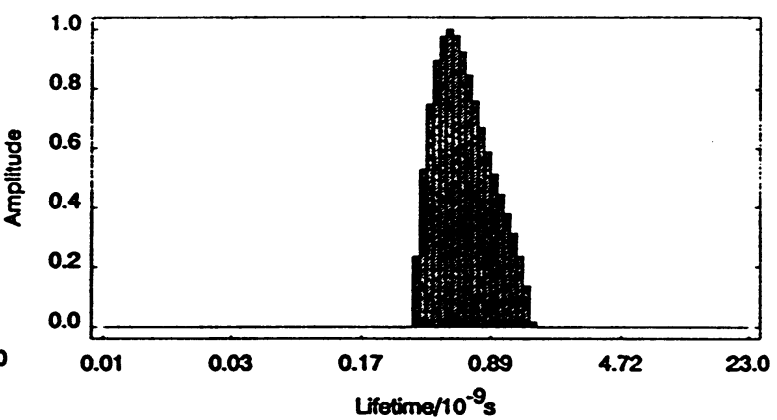

f

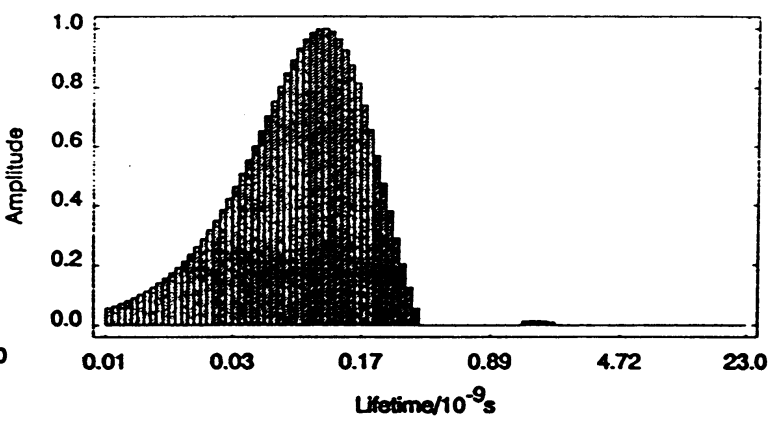

h

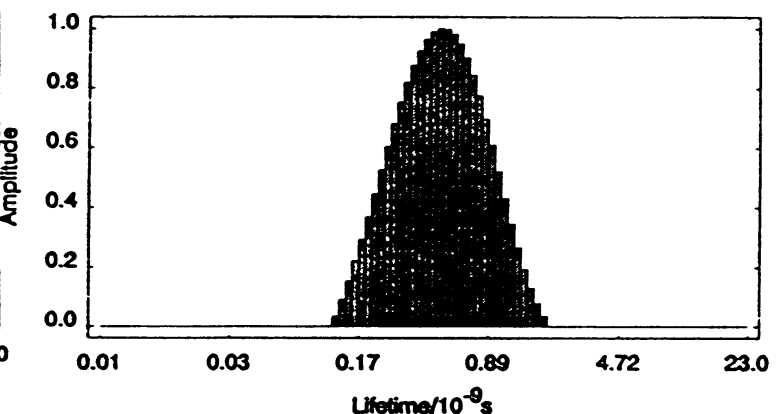

Figure 3. Lifetime distributions of the Trp fluorescence of Dns-[L-EN] (a), Dns-[D-EN] (b), F(NO ${ }_{2}$ )-[L-EN] (c), $\mathrm{F}\left(\mathrm{NO}_{2}\right.$ )-[D-EN] (d) in MeOH and Dns-[L-EN] (e), Dns-[D-EN] (f), F(NO ${ }_{2}$ )-[L-EN] (g), F(NO ${ }_{2}$ )-[D-EN] (h) in MeCN. 
acids in positions 1 and 4 are highly mobile, especially in the dansyl analogues. In solvents more polar than $\mathrm{MeOH}$ or $\mathrm{MeCN}$ the number of conformational families increases. The ability of water molecules to break the intramolecular hydrogen bonds increases the conformational freedom of the main peptide chain. The narrower lifetime distribution of the dansyl containing enkephalin analogues in more polar solvents (water and $\mathrm{Me}_{2} \mathrm{SO}$ ) may be associated with the tendency of hydrophobic aromatic side chains (Dns and Trp) to sticking to the main peptide chain, which is less hydrophobic than the solvent.

\section{R E F E R E N C E S}

1. Schiller, P.W. \& DiMaio, J. (1982) Opiate receptor subclasses differ in their conformational requirements. Nature 297, 74-76.

2. DiMaio, J., Nguyen, T.M.-D., Lemieux, C. \& Schiller, P.W. (1982) Synthesis and pharmacological characterization in vitro of cyclic enkephalin analogues: Effect of conformational constraints on opiate receptor selectivity. J. Med. Chem. 25, 1432-1438.

3. Mierke, D.F., Lucietto, P., Schiller, P.W. \& Goodman, M. (1987) Conformational studies of diastereomeric cyclic enkephalins by ${ }^{1} \mathrm{H}-\mathrm{NMR}$ and computer simulations. Biopolymers 26, 15731586.

4. Wilkes, B.C. \& Schiller, P.W. (1987) Theoretical conformational analysis of a $\mu$-selective cyclic opioid peptide analog. Biopolymers 26, 1431-1444.

5. Yamazaki, T., Said-Nejad, O.E., Schiller, P.W. \& Goodman, M. (1991) Conformational studies of stereoisomeric 14-membered cyclic enkephalin analogues containing 1-naphthylalanine at the fourth position: Chirality effect of leucine at the fifth position on biological activity and receptor selectivity. Biopolymers 31, 877-898.

6. Yamazaki, T., Mierke, D.F., Said-Nejad, O.E., Felder, E.R. \& Goodman, M. (1992) 14-Membered cyclic opioids related to dermorphin and their partially retro-inverso modified analogues. II. Preferred conformations in solution as studied by ${ }^{1}$ H-NMR spectroscopy. Int. J. Pept. Protein Res. 39, 161-181.
7. Wilkes, B.C., Zelent, B., Malak, H., Schmidt, R. \& Schiller, P.W. (1999) Interpretation of the fluorescence decay characteristic of cyclic $\beta$-casomorphin analogs based on theoretically calculated ensembles of their low energy conformers. Peptides, Fronties of peptide science. Proceedings of the Fifteenth American Peptide Symposium, 1997, Nashville, Tennessee, U.S.A. (Tam, J.P., Kaumaya, P.T. P., eds.) Kluwer Academic Press, Dordrecht, Boston, London.

8. Paterlini, M.G., Avitable, F., Ostrowski, B.G., Ferguson, D.M. \& Portoghese, P.S. (2000) Stereochemical requirements for receptor recognition of the $\mu$-opioid peptide endomorphin-1. Biophys. J. 78, 590- 599.

9. Alcala, J.R., Gratton, E. \& Prendegrast, F.G. (1987) Interpretation of fluorescence decays in proteins using continous lifetime distributions. Biophys. J. 51, 925-936.

10. Lakowicz, J.R., Gryczynski, I., Wiczk, W. \& Johnson, M.L. (1994) Distributions of fluorescence decay times for synthetic melittin in water-methanol mixture and complexed with calmodulin, troponin C, and phosphlipids. J. Fluoresc. 4, 169-177.

11. Swaminthan, R., Krishnamoorthy, G. \& Periasamy, N. (1994) Similarity of fluorescence lifetime distributions for single tryptophan proteins in the random coil state. Biophys. J. 67, 2013-2023.

12. Malicka, J., Groth, M., Czaplewski, C., Liwo, A. \& Wiczk, W. (1999) Fluorescence decay time distribution analysis of cyclic enkephalin analogues. Influence of the solvent and configuration of amino acids in position 2 and 3 on changes in conformation. Acta Biochim. Polon. 46, 615-629.

13. Szmacinski, H., Wiczk, W., Fishman, M.N., Eis, P.S., Lakowicz, J.R. \& Johnson, M.L. (1996) Distance distributions from the tyrosyl to disulfide residues in the oxitocin and $\left[\mathrm{Arg}^{8}\right]$-vasopressin measured using frequency-domain fluorescence resonance energy transfer. Eur. Biophys. J. 24, 185-193.

14. Wiczk, W., Łankiewicz, L., Kasprzykowski, F., Ołdziej, S., Szmacinski, H., Lakowicz, J.R. \& Grzonka, Z. (1997) Fluorescence study of neurohypophyseal hormones and their analogues. Distance distributions in series of argininevasopressin analogues. Eur. Biophys. J. 26, 183-193. 
15. Mierke, D.F., Schiller, P.W. \& Goodman, M. (1990) A conformational comparison of two stereoisomeric cyclic dermorphin analogues employing NMR and computer simulation. Biopolymers 29, 943-952.

16. Lakowicz, J.R., Cherek, H., Gryczynski, I., Joshi, N. \& Johnson, M.L. (1987) Analysis of fluorescence decay kinetics measured in the frequency-domain using distributions of decay times. Biophys. Chem. 27, 35-50.

17. Gryczynski, I., Wiczk, W., Lakowicz, J.R. \& Johnson, M.L. (1989) Decay time distribution analysis of $\mathrm{Y}_{\mathrm{t}}$-base in benzene-methanol mixtures. $J$. Photochem. Photobiol., B: Biology 4, 159-170.

18. Ferreira, S.T., Stella, L. \& Gratton, E. (1994) Conformational dynamics of bovine $\mathrm{Cu}, \mathrm{Zn}$ superoxide dismutase revealed by time-resolved fluorescence spectroscopy of the single tyrosine residue. Biophys. J. 66, 1185-1196.

19. Livesy, A.K. \& Brochon, J.-C. (1987) Analyzing the distribution of decay constants in pulse-fluorimetry using the maximum entropy method. Biophys. J. 52, 693-706.

20. Remacle, F. \& Levine, R.D. (1993) Time-domain information from frequency- or time-resolved experiments using maximum entropy. J. Phys. Chem. 97, $12553-12560$.

21. Brochon, J.-C. (1994) Maximum entropy method of data analysis in time-resolved spectroscopy. Methods Enzymol. 240, 262-311.

22. Swaminathan, R. \& Perisamy, N. (1996) Analysis of fluorescence decay by the maximum entropy method: Influence of noise and analysis parameters of the width of the distribution of lifetimes. Proc. Indian Acad. Sci. (Chem. Sci.) 108, 39-49.

23. Siemiarczuk, A., Wagner, B.D. \& Ware, W.R. (1990) Comparison of the entropy and exponential series methods for recovery of distributions of lifetimes from fluorescence lifetime data. J. Phys. Chem. 94, 1661-1666.

24. Landl, G., Langthaler, T., Engl, H.W. \& Kauffman, H.F. (1991) Distribution of event time in time-resolved fluorescence: The exponential series approach-algorithm, regularization, analysis. J. Comput. Phys. 95, 1-28.

25. Fields, G.B. \& Noble, R.L. (1990) Solid phase peptide synthesis utilizing 9-fluorenylomethoxycarbonyl amino acids. Int. J. Pept. Protein Res. 35, 161-214.

26. Schmidt, R. \& Neubert, K. (1991) Cyclization studies with tetra- and pentapeptide sequences corresponding to beta-casomorphins. Int. J. Pept. Protein Res. 37, 502-507.

27. Karolczak, J., Komar, D., Kubicki, J., Szymański, M., Wróżowo, T. \& Maciejewski, A. (1999) Fluorescence dynamics spectrometer of single-picosecond resolution: Optimisation of experimental performance. Bull. Pol. Acad. Sci. Chem. 47, 361-380.

28. Lakowicz, J.R. (1999) Protein fluorescence; in Principles of Fluorescence Spectroscopy (2nd edn.) pp. 446-486, Kluwer Academic/Plenum Publishers, New York, Boston, Dordrecht, London, Moscow. 